\title{
OBTENÇÃO DE ÉSTERES ETÍLICOS A PARTIR DA PRODUÇÃO DE BLENDAS PROVENIENTES DO REAPROVEITAMENTO DOS RESÍDUOS: SEBO BOVINO E ÓLEO DE FRITURA.
}

\author{
S. M. OLIVEIRA ${ }^{1}$, J. C. DALCOLLE ${ }^{2}$, L. A. FERREIRA ${ }^{3}$ e N. C. PEREIRA ${ }^{4}$ \\ ${ }^{1,2,3 \text { e } 4}$ Universidade Estadual de Maringá, Departamento de Engenharia Química \\ osordnas@yahoo.com.br
}

\begin{abstract}
RESUMO - O sebo bovino e o óleo de fritura surgem como uma grande alternativa de matérias-primas para produção de biodiesel. Além de possuir baixo custo, o óleo de fritura também auxilia na redução da acidez do sebo. Sendo assim, este trabalho teve como objetivo a formação de blendas para produção de biodiesel pelo processo de transesterificação, visando-se obter ésteres etílicos a partir da reciclagem de resíduos. As matérias-primas passaram por um tratamento físico e em seguida foi realizada a caracterização físico-química do sebo e do óleo. As blendas foram produzidas variando as misturas de 1 a $24 \mathrm{~g} / \mathrm{mol}$ totalizando $25 \mathrm{~g} / \mathrm{mol}$. As que permaneceram líquidas após $30 \mathrm{~min}$ à $-5^{\circ} \mathrm{C}$ seguidas de 24 horas à $25^{\circ} \mathrm{C}$ foram caracterizadas de acordo com a metodologia para as análises de índice de acidez, teor de umidade, índice de saponificação e massa específica. As blendas foram caracterizadas e submetidas à reação de transesterificação, sendo utilizado o ácido sulfúrico como catalisador. As blendas denominadas de 1 a 5 apresentaram resultados dentro dos padrões exigidos pela ANP, com isso foi realizado a cromatografia à gás para verificar o rendimento de conversão ocorrido em cada reação e, assim, percebeu-se, que apenas a blenda número 3 obteve conversão superior a 96\%, que é o exigido pela agencia. Conclui-se então, a partir dos resultados obtidos, a viabilidade de uso das blendas para a produção de ésteres etílicos, os quais podem ser classificados como biodiesel.
\end{abstract}

\section{INTRODUÇÃO}

Discussões com desenvolvimento sustentável e futuro do planeta vêm conduzindo a busca por tecnologias que tenham uma preocupação no mínimo satisfatória com o meio ambiente, evitando aumentar os danos causados com lançamentos de gases poluentes na atmosfera e a degradação de áreas ambientais, visando ainda, a viabilidade econômica em suas gerações e buscando o apoio político necessário para a sua criação. Tal interesse tem se traduzido em pesquisas acadêmicas, industriais e incentivos governamentais por processos ecologicamente corretos e economicamente viáveis que consigam substituir com a mesma eficiência as já existentes, como é o caso dos biocombustíveis. 


\section{9 a 22 de outubro de 2014 \\ Florianópolis/SC}

Biocombustíveis são derivados de biomassa renovável que podem substituir, parcial ou totalmente combustível fóssil e gás natural em motores a combustão ou em outro tipo de geração de energia (MAGALHÃES, 2010).

Os dois principais biocombustíveis líquidos usados no Brasil são o etanol extraído de canade-açúcar e, em escala crescente, o biodiesel, que é produzido a partir de óleos vegetais, de gorduras animais ou óleos residuais de indústrias, restaurantes e domicílios, chamados de cocção; essas matérias-primas após tratamento adequado podem ser submetidas a uma reação química com um álcool e um catalisador produzindo biodiesel, o qual pode ser utilizado isoladamente ou então adicionado ao diesel de petróleo em proporções variáveis. No resto do mundo, a maior parte das fontes de energia vem de fontes energéticas não renováveis. Pioneiro mundial no uso de biocombustíveis, o Brasil alcançou uma posição almejada por muitos países que buscam fontes renováveis de energia como alternativas estratégicas ao petróleo.

A questão ambiental constitui a verdadeira força motriz para a produção e consumo dos combustíveis limpos. A produção de biocombustíveis a partir de fontes renováveis é mais do que uma alternativa energética; constitui a base para um modelo de desenvolvimento tecnológico e industrial autônomo e autossustentado, baseado em dados concretos da realidade nacional e na integração do homem a uma realidade econômica em harmonia com o meio ambiente. Portanto, o desenvolvimento de novas tecnologias e formas de aproveitamento dos resíduos gerados pelas agroindustriais tem ganhado cada vez mais espaço e se torna uma fonte para redução dos impactos ambientais. Com isso, uma forma de aproveitamento dos resíduos, em especial os gordurosos, é a produção biodiesel (QUIAN, 2010).

A partir disso, e da busca de outras matérias-primas para a produção do biocombustível, descobriu-se o sebo do boi, que até então não tinha grande utilidade, e era descartando poluindo o meio ambiente; o mesmo acontece com a cocção (óleo de fritura). Vem daí, a ideia de unir os dois produtos para a produção do biodiesel, pois além de ser reciclada, a cocção também serve para diminuir a acidez do sebo, sem a necessidade de produtos inorgânicos para essa finalidade. Essas matérias-primas apresentam um potencial de oferta surpreendente, superando as mais otimistas expectativas na produção de biocombustível, e com isso a utilização para a produção de biodiesel, que acaba se tornando uma ótima alternativa e que irá gerar benefícios incalculáveis para a natureza.

Deste modo, este trabalho teve como objetivo a produção de biodiesel por meio da formação de blendas de sebo bovino com óleo de fritura pelo processo de transesterificação, visando-se obter um biocombustível a partir da reciclagem de resíduos.

\section{METODOLOGIA}

As matérias-primas passaram por tratamento e filtragem antes da caracterização. O sebo (1000 mL) foi dissolvido em $800 \mathrm{~mL}$ de éter de petróleo. A solução foi filtrada para remoção do material sólido e o solvente destilado em rotaevaporador $50^{\circ} \mathrm{C}$ sob vácuo $(-700 \mathrm{mmHg})$. Já o 


\section{9 a 22 de outubro de 2014 \\ Florianópolis/SC}

óleo de fritura após ser filtrado foi submetido em um sistema montado com um Kitassato sobre uma chapa aquecedora acoplado a uma bomba á vácuo, para homogeneização e secagem.

A caracterização das matérias-primas obteve-se a partir das analises, densidade feita pelo Densímetro digital Anton Paar modelo DMA 5000, Teor de Umidade pelo método ASTM D 4377 , Teor de Acidez método AOAC-940-28, Índice de saponificação pelo método AOCS Cd 3-52, Composição em ácidos graxos (cromatografia em fase gasosa). Concluída está etapa, foi efetuado o procedimento para formação das blendas: As misturas foram feitas em tubos de ensaio em diferentes proporções, variando a quantidade de óleo e sebo de 1 à $24 \mathrm{~g} / \mathrm{mol}$ obtendo no final cada blenda com $25 \mathrm{~g} / \mathrm{mol}$ da mistura. As mesmas foram agitadas manualmente para homogeneização e em seguida levadas para permanecerem em repouso em freezer a $-5^{\circ} \mathrm{C}$ seguidas de 24 horas a $25^{\circ} \mathrm{C}$, após este período, as misturas foram analisadas e selecionando as que permaneceram em estado liquido, definindo-as como as misturas ideais para este experimento, o que possibilitou a realização da reação de transesterificação em catalise ácida, sendo utilizado o ácido sulfúrico como catalisador e etanol como álcool.

Após o fim da reação, a mistura foi transferida para um balão de fundo redondo de 1000 $\mathrm{mL}$ e colocado em um rotaevaporador, para recuperar o álcool em excesso deixando apenas o produto reagido. Em seguida, o produto foi mantido em repouso em um funil de decantação de fases, onde foram separadas ambas as fases formadas, glicerina e ésteres A glicerina é retirada, e os ésteres etílicos foram submetidos à lavagem no próprio funil de decantação com água destilada a $90^{\circ} \mathrm{C}$, na razão $1: 5$ de água para o produto reacional. $\mathrm{O}$ funil foi agitado simulando a lavagem para a retirada de impurezas (álcool não reagido, catalisador e sabões formados durante a reação) por parte da água. Após repouso, a água por ser a fase mais densa ficará na parte inferior e o biodiesel na parte superior permitindo que fossem separadas a partir da decantação, e assim, a água impura foi removida e posteriormente descartada deixando somente os ésteres etílicos formado na transesterificação.

Terminada a lavagem, o produto foi submetido ao processo de secagem em estufa a $105^{\circ} \mathrm{C}$ por 3 horas, onde foi removidas possíveis gotículas de água que tenham permanecido em contado com o produto, para que assim fosse realizado as analises para controle de qualidade, o qual foi analisado: Cromatografia a gás para determinação dos ésteres, aspecto, índice de acidez, viscosidade a $40^{\circ} \mathrm{C}$ e teor de glicerol livre.

\section{RESULTADOS E DISCUSSÕES}

Inicialmente foi realizada a cromatografia em fase gasosa para identificar os ácidos graxos presentes, obtendo resultados de acordo com a Tabela 1. Conforme o já apresentado por, as matérias-primas apresentam como ácidos graxos predominantes no óleo e no sebo respectivamente, Ácido Linoleico (C18:2n6c) e Ácido Oleico (C18:1n9c). 
Tabela 1 - Cromatografia em fase gasosa.

ÓLEO DE FRITURA

\section{CROMATOGRÁFIA EM FASE GASOSA}

Ácido graxo

Ácido Mirístico (C14:0)

Ácido Palmítico (C16:0)

Ácido Palmitoléico (C16:1)

Ácido Esteárico (C18:0)

Ácido Oleico (C18:1n9c)

Ácido Linoleico (C18:2n6c)

Ácido Linolênico (C18:3n3)

Ácido Erúcico (C22:1n9)
SEBO BOVINO

Ácido graxo

Ácido Mirístico (C14:0)

$\%$

1,4

21,1

5,5

26,3

42,2

2,3

Conforme apresentado nesses resultados e de acordo com apresentado por ALBA (2010), percebe-se uma alta concentração dos óleos oleico e linoleico, representando aproximadamente $60 \%$ do total dos principais ácidos graxos identificados.

Em seguida foi realizado o acompanhamento mensal durante doze meses das matériasprimas para que pudessem ser verificadas possíveis alterações. De acordo com apresentado na Tabela 2, Os resultados ilustram que o índice de acidez e o teor de umidade no óleo de fritura estão abaixo do limite considerado aceitável para produção de biodiesel $(2 \mathrm{mg} \mathrm{KOH} / \mathrm{g}$ óleo e 0,5 $\%$, respectivamente, segundo Portaria 042/2004 da ANP).

Tabela 2. Caracterização mensal do óleo de fritura.

\begin{tabular}{|c|c|c|c|c|}
\hline & \multicolumn{4}{|c|}{ Caracterização óleo de fritura } \\
\hline & Umidade (\%) & $\begin{array}{l}\text { Índice de Acidez } \\
\text { (mg KOH/g óleo) }\end{array}$ & $\begin{array}{c}\text { Índice de } \\
\text { Saponificação } \\
\text { (ma KOH/a óleo) }\end{array}$ & $\begin{array}{c}\text { Densidade } \\
(\mathrm{g} / \mathrm{mL})\end{array}$ \\
\hline Dez & 0,110 & $1,15 \pm 1,12$ & $201,0 \pm 1,15$ & 0,917744 \\
\hline Jan & 0,180 & $1,19 \pm 0,03$ & $201,99 \pm 0,39$ & 0,913703 \\
\hline Fev & 0,188 & $1,22 \pm 0,06$ & $194,97 \pm 2,26$ & 0,91668 \\
\hline Mar & 0,133 & $1,20 \pm 0,04$ & $201,29 \pm 2,09$ & 0,92222 \\
\hline Abr & 0,113 & $1,19 \pm 0,04$ & $197,36 \pm 3,15$ & 0,917840 \\
\hline Mai & 0,196 & $1,27 \pm 0,02$ & $197,12 \pm 4,50$ & 0,916756 \\
\hline Jun & 0,262 & $1,39 \pm 0,02$ & $198,71 \pm 1,40$ & 0,915388 \\
\hline Jul & 0,195 & $1,30 \pm 0,05$ & $197,21 \pm 1,55$ & 0,918860 \\
\hline Ago & 0,152 & $1,25 \pm 0,05$ & $198,71 \pm 1,40$ & 0,907521 \\
\hline Set & 0,143 & $1,18 \pm 0,03$ & $189,76 \pm 4,40$ & 0,907758 \\
\hline Out & 0,112 & $1,15 \pm 0,09$ & $190,54 \pm 1,20$ & 0,896789 \\
\hline Nov & 0,125 & $1,20 \pm 0,01$ & $200,99 \pm 1,30$ & 0,899978 \\
\hline
\end{tabular}

Já para o sebo de boi, os dados de índice de acidez mostram que sua taxa tem um valor consideravelmente alto ao estabelecido pelas normas brasileiras para produção de 
biocombustível; conforme mostra a Tabela 3 (2 mg KOH/g óleo segundo Portaria 042/2004 da ANP).

Tabela 3 - Caracterização mensal do sebo bovino.

\begin{tabular}{lcccc}
\hline & $\begin{array}{c}\text { Umidade } \\
(\%)\end{array}$ & $\begin{array}{c}\text { Caracterização Sebo bovino } \\
\text { (mg KOH/g óleo) }\end{array}$ & $\begin{array}{c}\text { Índice de Saponificação } \\
(\mathrm{mg} \mathrm{KOH/g} \text { óleo })\end{array}$ & $\begin{array}{c}\text { Densidade } \\
(\mathrm{g} / \mathrm{mL})\end{array}$ \\
Dez & 0,102 & $11,98 \pm 0,65$ & $210,0 \pm 0,62$ & 0,896151 \\
Jan & 0,137 & $14,39 \pm 0,43$ & $201,49 \pm 0,89$ & 0,896156 \\
Fev & 0,152 & $19,54 \pm 0,84$ & $198,46 \pm 5,45$ & 0,898821 \\
Mar & 0,162 & $20,12 \pm 1,77$ & $212,89 \pm 1,31$ & 0,892359 \\
Abr & 0,176 & $20,7 \pm 1,44$ & $211,38 \pm 2,09$ & 0,896786 \\
Mai & 0,230 & $20,96 \pm 1,60$ & $201,19 \pm 2,09$ & 0,897236 \\
Jun & 1,754 & $23,47 \pm 1,27$ & $197,54 \pm 2,65$ & 0,897800 \\
Jul & 1,890 & $23,59 \pm 1,20$ & $200,07 \pm 1,42$ & 0,895482 \\
Ago & 0,219 & $21,88 \pm 0,03$ & $213,71 \pm 2,71$ & 0,895666 \\
Set & 0,202 & $20,84 \pm 0,38$ & $196,61 \pm 7,46$ & 0,893456 \\
Out & 0,198 & $20,71 \pm 0,45$ & $190,57 \pm 3,96$ & 0,905478 \\
Nov & 0,197 & $18,17 \pm 0,95$ & $196,41 \pm 0,30$ & 0,909874 \\
\hline
\end{tabular}

Já para o sebo de boi, os dados de índice de acidez mostram que sua taxa tem um valor consideravelmente alto ao estabelecido pelas normas brasileiras para produção de biocombustível

O estado físico a temperatura ambiente da blenda durante seu processamento é de grande importância tecnológica para avaliar a viabilidade do projeto, especialmente em operação batelada, onde, a energia será necessária em cada repetição no aquecimento e transporte de matérias-primas.

As blendas foram produzidas atravez da mistura em diferentes proporções de oleo de fritura e sebo de boi, de acordo com o procedimento já especificado na metodologia.

A temperatura ambiente determinada para o procedimento foi de $25^{\circ} \mathrm{C}$ (Maringá, PR). Nessas condições as blendas com mais de $40 \%$ foram solidas. Misturas que apresentavam ponto de névoa, que é quando o primeiro sólido surge, foram descartadas (entre 29 e 39\% de sebo), pois o interesse do projeto é para as que apresentassem estado liquido apos o procedimento descrito. Isso ocorreu com as blendas com menos de $28 \%$ de sebo, conforme representado na Tabela 4.

Tabela 4 - Proporção das blendas Óleo de fritura:Sebo bovino

\begin{tabular}{|c|c|c|c|c|c|}
\hline $\begin{array}{c}\text { Blenda } \\
1\end{array}$ & $\begin{array}{c}\text { Proporção } \\
\text { Cocção:Sebo } \\
24: 1\end{array}$ & $\begin{array}{l}\text { Estado físico } \\
\text { Líquido }\end{array}$ & $\begin{array}{c}\text { Blenda } \\
13\end{array}$ & $\begin{array}{c}\text { Proporção } \\
\text { Cocção:Sebo } \\
12 \cdot 13\end{array}$ & $\begin{array}{c}\text { Estado físico } \\
\text { Sólido }\end{array}$ \\
\hline
\end{tabular}




\begin{tabular}{cccccc}
\hline 2 & $23: 2$ & Líquido & 14 & $11: 14$ & Sólido \\
3 & $22: 3$ & Líquido & 15 & $10: 15$ & Sólido \\
4 & $21: 4$ & Líquido & 16 & $9: 16$ & Sólido \\
5 & $20: 5$ & Líquido & 17 & $8: 17$ & Sólido \\
6 & $19: 6$ & Líquido & 18 & $7: 18$ & Sólido \\
7 & $18: 7$ & Líquido & 19 & $6: 19$ & Sólido \\
8 & $17: 8$ & Pastoso & 20 & $5: 20$ & Sólido \\
9 & $16: 9$ & Pastoso & 21 & $4: 21$ & Sólido \\
10 & $15: 10$ & Pastoso & 22 & $3: 22$ & Sólido \\
11 & $14: 11$ & Sólido & 23 & $2: 23$ & Sólido \\
12 & $13: 12$ & Sólido & 24 & $1: 24$ & Sólido \\
\hline
\end{tabular}

.Sabendo que o responsável pela elevação do índice de acidez na mistura é o sebo bovino, e da influência dessa variável na conversão foi efetuada a caracterização dessas blendas conforme Tabela 5.

Tabela 5 - Caracterizações das blendas liquidas selecionadas.

Caracterização das blendas

Índice de Acidez Índice de Saponificação (mg Densidade Umidade (\%) (mg KOH/g óleo $\quad \quad \mathrm{KOH} / \mathrm{g}$ óleo $) \quad(\mathrm{g} / \mathrm{mL})$

\begin{tabular}{lllll} 
Blenda 1 & 0,139 & 2,48 & $169,11 \pm 0,32$ & 0,892489 \\
Blenda 2 & 0,140 & 3,03 & $173,79 \pm 0,24$ & 0,893112 \\
Blenda 3 & 0,138 & 3,84 & $180,80 \pm 0,54$ & 0,894025 \\
Blenda 4 & 0,139 & 4,66 & $179,28 \pm 0,13$ & 0,900252 \\
Blenda 5 & 0,136 & 5,21 & $181,35 \pm 0,25$ & 0,911123 \\
Blenda 6 & 0,137 & 6,09 & $185,93 \pm 0,43$ & 0,922187 \\
Blenda 7 & 0,134 & 6,65 & $184,68 \pm 0,39$ & 0,925897 \\
\hline
\end{tabular}

A partir das caracterizações das blendas selecionadas, foi realizada a transesterificação das mesmas para verificar quais conseguiriam realizar a conversão e se poderiam ser classificadas como Biodiesel. Após a reação efetuou-se então as análises para controle de qualidade dos ésteres etílicos produzidos.

Com a descoberta da melhor mistura, teremos resultado de qualidade obtida a partir da reciclagem de resíduos que possuem finalidades ainda incertas no âmbito ambiental. Tabela 6.

De acordo com as analises realizadas obtemos os seguintes resultados, apresentados na 
Tabela 6 - Dados das análises para controle de qualidade dos ésteres etílicos produzidos.

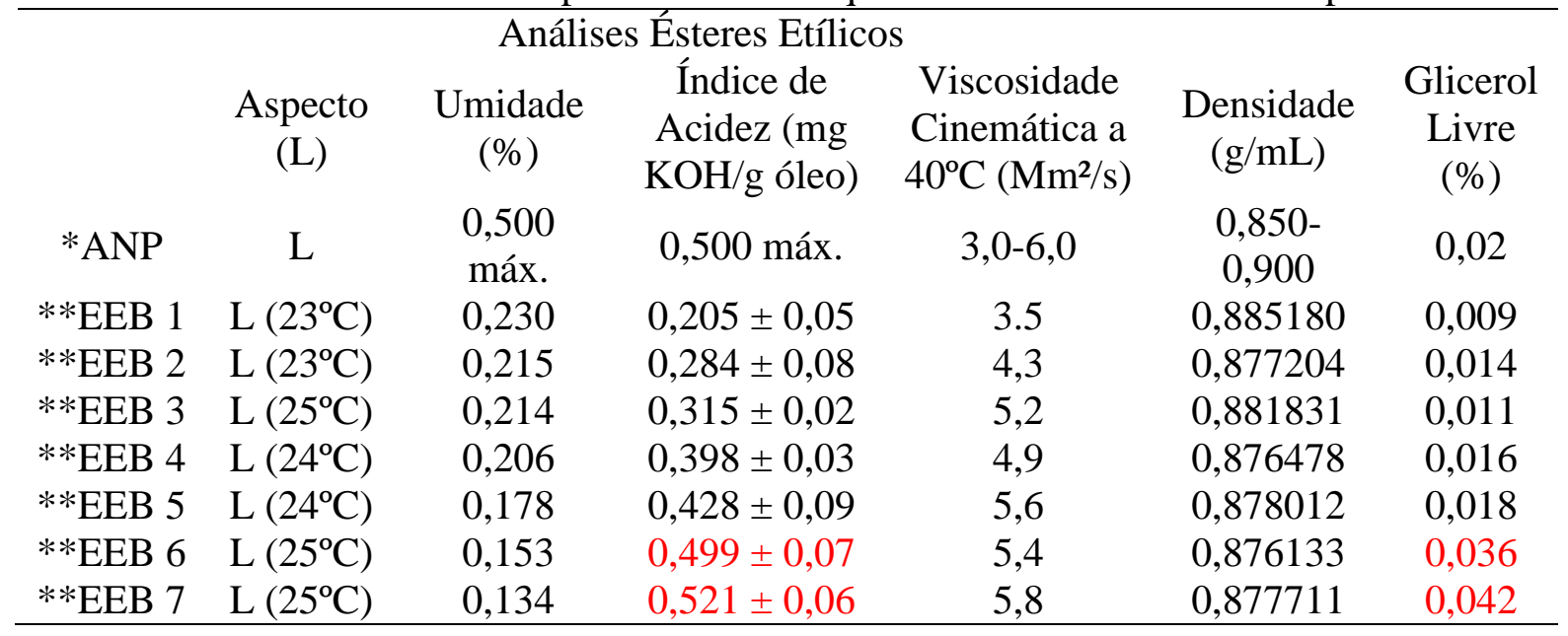

Com base nos valores apresentados na tabela percebe-se que as blendas de 1 à 5 tiveram resultados satisfatórios e dentro dos padrões de analise para controle de qualidade exigidas pela ANP, resolução ANP $\mathrm{n}^{\mathrm{o}}$ 14, de 11.5.2012 - DOU 18.5.2012, no entanto, as blendas 6 e 7 apresentaram resultados para índice de acidez e teor de glicerol livre acima dos limite, sendo assim, descartadas as misturas com porcentagens acima de $20 \%$.

Foi realizada a cromatografia para verificar e analisar a se realmente ocorreu à conversão durante a reação de acordo com a Figura 1.

Conforme verificado, as 5 blendas produziram os mesmos ésteres, ácido palmítico, esteárico, oleico e linoleico, porem, em concentrações diferentes, como apresentado por MAGALHÃES (2010). De acordo com a quantidade de sebo presente em cada blenda variou a quantidade de ácido presente em sua reação.

A partir disso, foi analisado o rendimento para as 5 primeiras blendas, obtendo resultados apresentados na tabela 7. Levando em consideração o fato de que o rendimento de produção diminui quando utilizada matérias-primas com índice de acidez superior a 3\%, podemos determinar que as misturas ideias de acordo com este projeto são as blendas com até $12 \%$ de sebo.

Tabela 7 - Rendimento das blendas na produção de ésteres etílicos.

\begin{tabular}{llll}
\hline Amostras & $\begin{array}{l}\text { Rendimento } \\
\text { Bruto (\%) }\end{array}$ & $\begin{array}{l}\text { Rendimento Purificado } \\
\text { por Lavagem (\%) }\end{array}$ & $\begin{array}{l}\text { Perdas (Lavagem } \\
\%)\end{array}$ \\
Blenda 1 & 97,5 & 93,5 & 4 \\
Blenda 2 & 94,6 & 85,4 & 9,2 \\
Blenda 3 & 99,5 & 96,7 & 2,8 \\
Blenda 4 & 94,1 & 90,2 & 3,9 \\
Blenda 5 & 90,3 & 82,7 & 7,5 \\
\hline
\end{tabular}


De acordo com os resultados apresentados na tabela, foi possível verificar o rendimento obtido em cada conversão e quais encontraram dentro dos padrões exigidos pela ANP. Para ser considerado biodiesel o rendimento final, após purificação, deve ser de pelo menos 96,5\%. Isso ocorre apenas na reação feita com a blenda numero três, concluindo que ela foi a única capaz de atingir todas as exigências da ANP para as análises realizadas neste trabalho, obtendo rendimento final depois de purificada de $96,7 \%$, superior ao exigido.

Se relacionarmos com o trabalho desenvolvido por MAGALHÃES (2010), onde o rendimento da reação de transesterificação feita a partir de blendas de sebo bovino e óleo de soja, foi de apenas $64 \%$, conseguiremos perceber o potencial que essas matérias-primas possuem unificadas.

\section{CONCLUSÃO}

A partir dos resultados obtidos, verificou-se que as blendas obtidas foram viáveis para a produção do biodiesel, apresentando-se uma nova materia-prima para a produção de um biocombustível que estejam dentro dos padrões de exigência e qualidade.

Enfim, a produção de blendas líquidas que tenham grande eficiência comparada aos outros tipos de matéria prima é possível. As misturas que permaneceram em estado líquido foram analisadas no cromatógrafo e apresentaram bons resultados com características que viabilizam a produção de um biocombustível de qualidade. O biodiesel produzido atendeu por fim a todos os quesitos exigidos para utilização como biocombustível liquido dentro das normas nacionais, atingindo o objetivo deste trabalho. Este tipo de produção de blendas em escala industrial tem potencial para ser um investimento promissor que agrega grande valor econômico e socioambiental.

\section{REFERÊNCIAS}

ALBA, Marcelo J. Caracterização do sebo bovino e do óleo A1 utilizados como combustíveis em caldeiras para geração de vapor. Belo Horizonte: $4^{\circ}$ Congresso da RBTB, $7^{\circ}$ Congresso Brasileiro de Plantas Oleaginosas, óleos, gorduras e Biodiesel, lavras: UFLA, (2010) 81 p.

INSTITUTO ADOLFO LUTZ, Métodos físico-químicos para análise de alimentos. Coordenadores Odair Zenebon, Neus Sadocco Pascuet e Paulo Tiglea, 4a edição, São Paulo: Instituto Adolfo Lutz, 2008.

MAGALHÃES, FABIO CARVALHO. Blenda sebo/soja para produção de biodiesel: proposta de um processo batelada homogêneo como alternativa para agricultura familiar, 2010. 77p.

QIAN, J.; SHI, H.; YUN, Z.; Preparation of biodiesel from jatropha curcas L. oil produced by two phase solvent extraction. bioresource technology 2010, 101, 18, 7025-7031. 